\title{
A novel combined needle-knife and standard sphincterotome: the dualtome
}

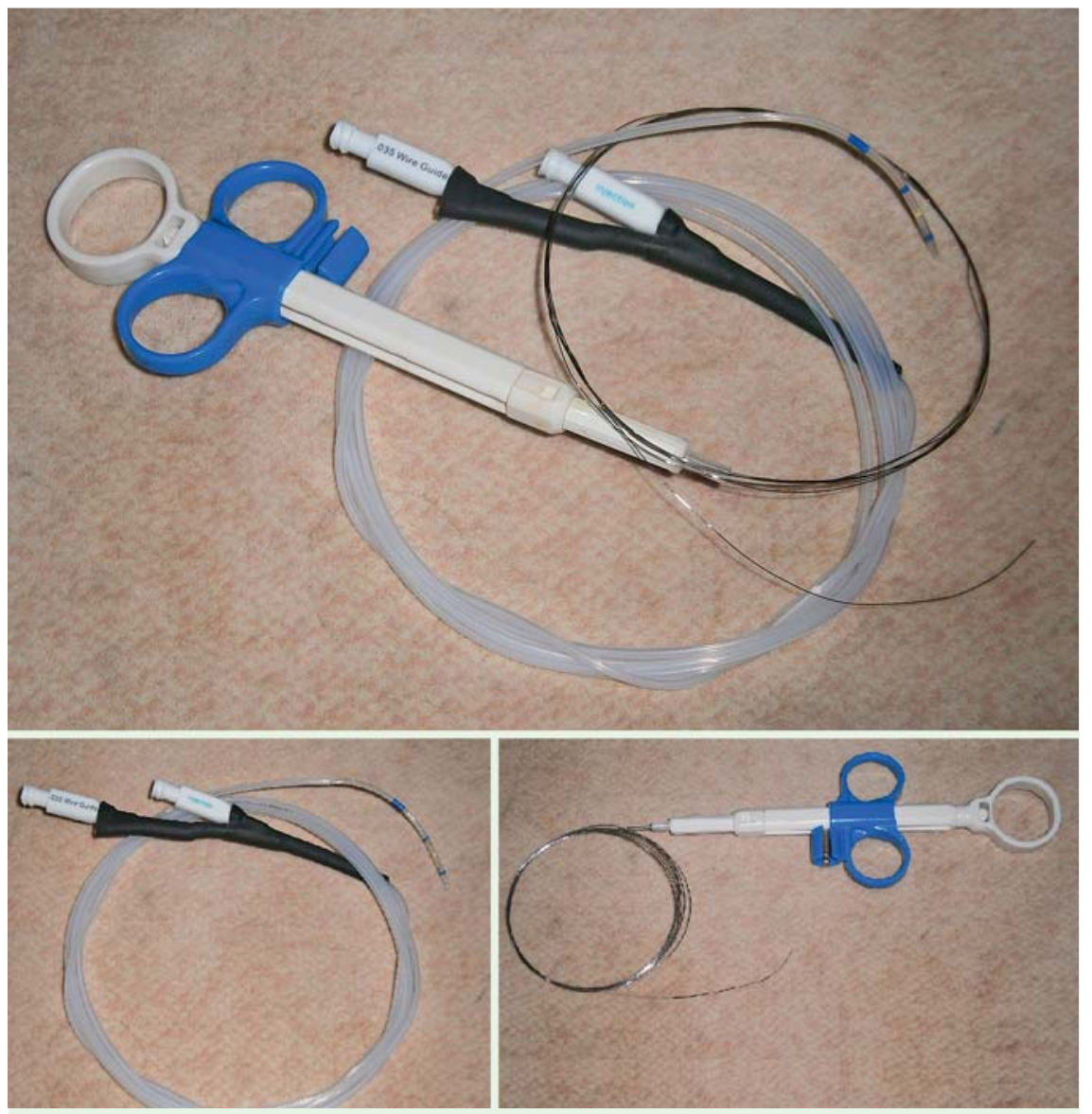

Fig. 1 Photographs showing how the cutting wire of the dualtome is created with a string that is disconnected from a standard sphincterotome.

Needle-knife sphincterotomes are usually used during endoscopic retrograde cholangiopancreatography (ERCP) when standard cannulation methods with a cannula alone or even with a standard sphincterotome have failed, but as yet the combination of a standard sphincterotome and a needle-knife sphincterotome has not been used simultaneously. We present a novel sphincterotome, named the "dualtome," that has the features and abilities of both standard and needleknife sphincterotomes.

To create a dualtome, we first need a needle-knife wire that has a handle for electrical connections. The cutting wire of a standard sphincterotome is disconnected with a cut at the distal tip of the sphincterotome and the handle of the standard sphincterotome is then separated by cut- ting the proximal plastic sheath of the sphincterotome while preserving the cutting string. The string is taken out of this standard sphincterotome to be used as the cutting wire for the needle-knife sphincterotome ( Fig. 1). The needleknife sphincterotome is created by gently loading the string into the injection channel of another new standard sphincterotome. The handle connected to the string is fixed to the orifice of the injection channel and the distal tip of the string is then cut and calibrated to a length of $5 \mathrm{~mm}$, which is the same as a standard needleknife while in cutting position. Once the guidewire has been loaded into its channel, the dualtome is ready to be used for both needle-knife and standard sphincterotomies ( $\bullet$ Fig. 2).

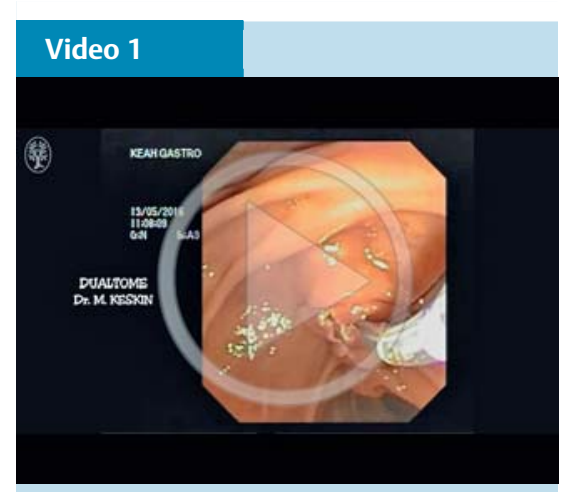

A dualtome is used for selective biliary cannulation with the fistulotomy method in a patient with a biliary stone.

The string can be easily removed to use the injection channel for other purposes after cannulation or needle-knife procedures have been completed. The dualtome has two separate handles for each of the sphincterotomy procedures and this makes the electrical connections and the method easier and more feasible. Dualtome is applied for selective biliary cannulation as a demonstration ( Video 1 ).

The dualtome is a needle-knife sphincterotome that has the bowing ability of a standard sphincterotome. The bowing maneuver enhances the cutting ability of the dualtome, making it safer and easier to use when compared with a needleknife sphincterotome. In addition, the dualtome still has the features of a standard sphincterotome, meaning it is possible to easily change between the different types of sphincterotome or use both simultaneously without wasting time and effort during any ERCP procedures. This report also describes a novel method for cannulation using the features of both standard and needle-knife sphincterotomes, as in the dualtome. Manufacture of a dualtome that worked independently of the injection channel would make it widely applicable and useful in ERCP procedures.

Endoscopy_UCTN_Code_TTT_1AR_2AC

Competing interests: None 


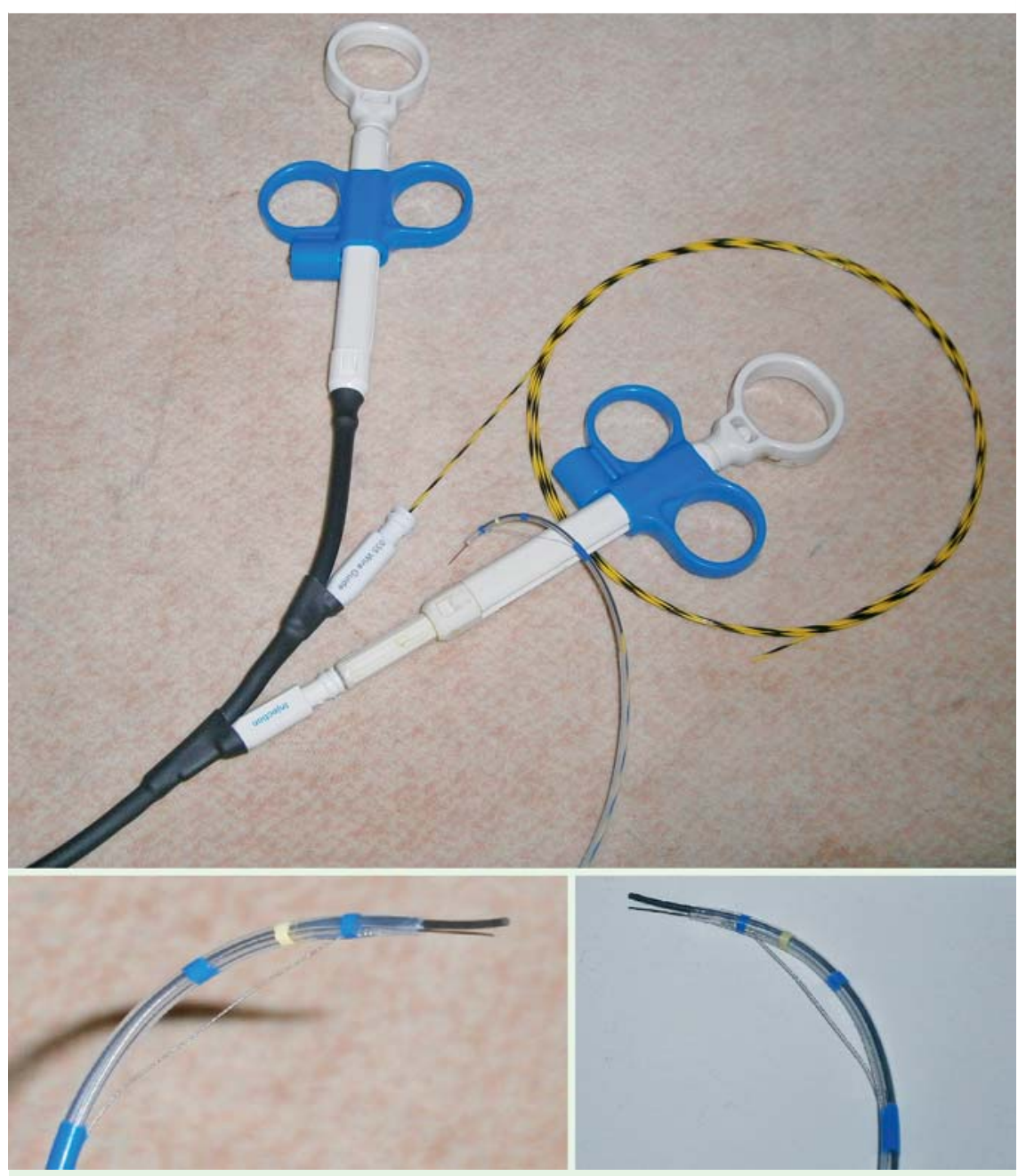

\section{Muharrem Keskin}

Department of Gastroenterology and Hepatology, Konya Training and Research Hospital, Konya, Turkey

\section{Bibliography}

DOI http://dx.doi.org/

10.1055/s-0042-120706

Endoscopy 2016; 48: E396-E397

(c) Georg Thieme Verlag KG

Stuttgart · New York

ISSN 0013-726X

\section{Corresponding author}

\section{Muharrem Keskin, MD}

Konya Training and Research Hospital

Department of Gastroenterology and Hepatology Meram, Konya

Turkey

Fax: 90-332-3236723

muharrem.keskin@gmail.com

Fig. 2 The dualtome has two separate handles; the string has been loaded into the injection channel and its tip has been calibrated to a length of $5 \mathrm{~mm}$; the guidewire has been loaded into its own channel. 